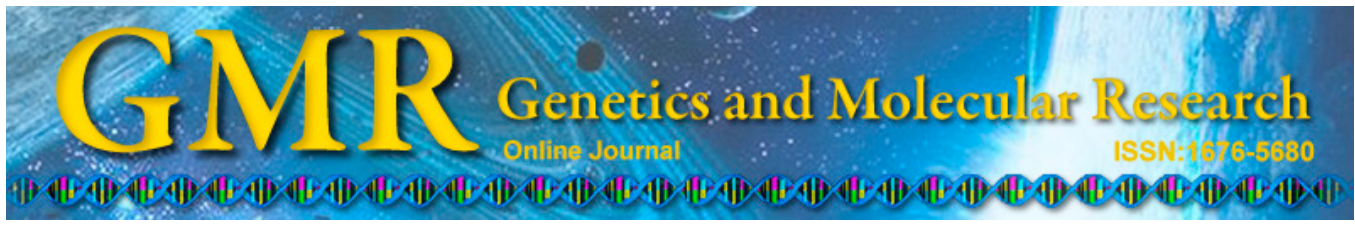

\title{
Reaction of common bean lines and aggressiveness of Sclerotinia sclerotiorum isolates
}

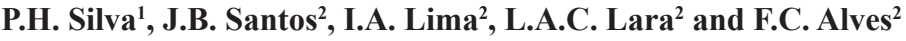 \\ ${ }^{1}$ Centro de Ciências Agrárias, Ambientais e Biológicas, \\ Universidade Federal do Recôncavo da Bahia, Cruz das Almas, BA, Brasil \\ ${ }^{2}$ Departamento de Biologia, Universidade Federal de Lavras, \\ Lavras, MG, Brasil
}

Corresponding author: P.H. Silva

E-mail: pphsilva@hotmail.com

Genet. Mol. Res. 13 (4): 9138-9151 (2014)

Received December 10, 2013

Accepted March 26, 2014

Published November 7, 2014

DOI http://dx.doi.org/10.4238/2014.November.7.11

\begin{abstract}
The aims of this study were to evaluate the reaction of common bean lines to white mold, the aggressiveness of different Sclerotinia sclerotiorum isolates from various common bean production areas in Brazil, and comparison of the diallel and GGE (genotype main effect plus genotype-by-environment interaction) biplot analysis procedures via study of the line-by-isolate interaction. Eleven common bean (Phaseolus vulgaris) lines derived from 3 backcross populations were used. Field experiments were performed in the experimental area of the Departamento de Biologia of the Universidade Federal de Lavras, Lavras, MG, Brazil, in the 2011 and 2012 dry crop season and 2011 winter crop season through a randomized block design with 3 replications. This study was also set up in a greenhouse. Inoculations were performed 28 days after sowing by means of the straw test method. The reaction of the bean lines to white mold was assessed according to a diagrammatic scale from 1 (plant without symptoms) to 9 (dead plant). Estimations of general reaction capacity (lines) and general aggressiveness capacity (isolates) indicated different horizontal levels
\end{abstract}


of resistance in the lines and levels of aggressiveness in the isolates. Therefore, it was possible to select more resistant lines and foresee those crosses that are the most promising for increasing the level of resistance. It was also possible to identify the most aggressive isolates that were more efficient in distinguishing the lines. Both diallel and GGE biplot analyses were useful in identifying the genotypic values of lines and isolates.

Key words: Phaseolus vulgaris; Resistance; Line-by-isolate interaction; Straw test

\section{INTRODUCTION}

White mold, which is caused by the fungus Sclerotinia sclerotiorum (Lib.) de Bary, is a disease that may lead to great losses in the common bean (Phaseolus vulgaris) crop and is currently regarded as one of the most important diseases. The common bean is grown throughout the world (Voysest, 2000) and Brazil is among its main producers. Brazil is also the world's largest consumer of the crop. The fungus $S$. sclerotiorum is necrotrophic and polyphagous; plants from 75 families, 278 genera, and 408 species are carrier hosts (Boland and Hall, 1994). The disease may cause up to an $80 \%$ reduction in yield and may remain viable in the soil for up to 15 years through its resistance mechanisms (Lobo Jr. and Nasser, 2007). The fungus is able to infect any part of the plant; however, infections most frequently begin at the flowers fallen in the leaf axils and lateral branches (Kimati et al., 2005). Some studies have shown its complex inheritance, which is associated with partial physiological resistance and escape mechanisms, such as climatic conditions and morphological traits (Miklas et al., 2001; Kolkman and Kelly, 2003; Huang et al., 2003; Soule et al., 2011). Plant architecture stands out as one of the main morphological traits that affects microclimatic conditions and limits the development of the pathogen (Kolkman and Kelly, 2002; Huang et al., 2003).

There are various methodologies for assessing white mold resistance in the common bean. One of the simplest, also regarded as the most efficient for assessing physiological resistance is the straw test (Petzoldt and Dickson, 1996; Terán et al., 2006); it is also one of the most used methodologies for characterizing and selecting white mold resistant genotypes (Terán and Singh, 2008). The straw test is also the most highly used method in controlled environments and has good correlation with field tests (Miklas et al., 2001; Ender and Kelly, 2005; Maxwell et al., 2007; Terán and Singh, 2009). Field evaluation in already contaminated soil is generally more difficult, especially because of the irregular distribution of the inoculum. Kim et al. (2000) found that the genotype-by-environment interaction was significant in field evaluations. However, field evaluation through the straw test ensures the presence of the pathogen and development of the disease using the same crop conditions, without the space limitation that occurs in controlled environments (Carneiro et al., 2011). Moreover, the ability to assess both physiological resistance and escape mechanisms is another advantage of field inoculation under crop conditions.

For analysis of the host-by-pathogen interaction, the data regarding reaction of genotypes to $S$. sclerotiorum isolates have been commonly assessed by ANOVA. However, a methodology using a partial diallel arrangement, as proposed by Melo and Santos (1999), has proven to be efficient in distinguishing horizontal and vertical resistance, pathogen aggressiveness, and estimating the genetic effect of resistance from each line and aggressiveness 
from each isolate (Buiate et al., 2010; Carneiro et al., 2011; Pereira, 2013). A GGE biplot analysis is another methodology that may be used to determine the levels of host resistance and isolate aggressiveness (Yan and Kang, 2002). Both methods also allow for the study of isolate and line stabilities.

The aims of this study were to evaluate the reaction of common bean lines to white mold, the aggressiveness of different $S$. sclerotiorum isolates from various common bean production areas in the central-west and southeast regions of Brazil, and comparison of the diallel and genotype main effect plus genotype-by-environment interaction (GGE) biplot analysis procedures to determine the level of resistance (lines), level of aggressiveness (isolates), and contribution of the line-by-isolate interaction.

\section{MATERIAL AND METHODS}

\section{Lines}

Three backcross populations were used for selecting 11 common bean (Phaseolus vulgaris) lines, including lines 10, 14, 28, 125, 138, and 667 from the backcrosses Madrepérola (Madrepérola x G122) and Madrepérola (Madrepérola x Ex Rico 23); lines 19, 88, 89, 92, and 112 from the backcross $\{$ M20 x [M20 x (M20 x G122)]\} (Lima et al., 2009); and the whitemold-susceptible Corujinha line as the control. The G122 and Ex Rico 23 lines are known sources of physiological resistance to white mold (Miklas et al., 2001; Kolkman and Kelly, 2003); however, they are not adapted to Brazilian growth conditions or the Brazilian market. G122 has a large spotted seed and exhibits type I growth, Ex Rico 23 has a small white seed and exhibits type II growth; both have good levels of partial physiological resistance to white mold. The M20 and Madrepérola lines have low levels of physiological resistance to white mold; however, they have a carioca seed (light cream coloration with light brown stripes) with high market acceptance in Brazil (Madrepérola cultivar, in particular) and high grain yield.

\section{Origin and inoculum preparation of $S$. sclerotiorum isolates}

Twenty-two S. sclerotiorum isolates from different locations in the states of Minas Gerais and Goiás, Brazil, were used; they were obtained from the Fungus Collection of the Plant Disease Resistance Laboratory at the Universidade Federal de Lavras (Table 1). The isolates were collected from common bean fields.

\begin{tabular}{|c|c|c|c|}
\hline No./isolate & Origin & No./isolate & Origin \\
\hline I1-(Ijaci 05) & Ijaci, MG & I12-(UFLA27) & Lambari, MG \\
\hline I2-(UFLA29) & Lambari, MG & I13-(UFLA28) & Lambari, MG \\
\hline I3-(UFLA37) & Viçosa, MG & I14-(UFLA49) & Porto Firme, MG \\
\hline I4-(UFLA38) & Presidente Bernardes, MG & I15-(UFLA48) & Oratórios, $\mathrm{MG}$ \\
\hline I5-(UFLA39) & Cabeceira Grande, MG & I16-(UFLA66) & Unaí, MG \\
\hline I6-(UFLA44) & Coimbra, MG & I17-(UFLA91) & Patos de Minas, MG \\
\hline I7-(UFLA47) & Paracatu, MG & I18-(UFLA10) & Ijaci, MG \\
\hline I8-(Goiânia4) & Goiânia, GO & I19-(UFLA22) & Lambari, MG \\
\hline I9-(UFLA36) & Guarda Mor, MG & I20-(UFLA34) & Paracatu, MG \\
\hline I10-(UFLA30) & Lambari, MG & I21-(UFLA46) & Oratórios, MG \\
\hline I11-(UFLA03) & Ijaci, MG & I22-(UFLA51) & Viçosa, MG \\
\hline
\end{tabular}


Initially, the sclerotia were subjected to asepsis and placed on petri dishes with a potato dextrose agar (PDA) medium with the antibiotic chloramphenicol. They were then kept in an incubation chamber for 4 days at $22^{\circ} \mathrm{C}$ with a 12-h photoperiod to promote fungal growth. After mycelium was obtained, a 0.7-mm diameter punch device was used to chop it up. Disks were placed on new petri dishes containing the PDA medium for the purpose of multiplying the mycelium and obtaining more uniform growth. The petri dishes were then placed in an incubation chamber for $72 \mathrm{~h}$.

\section{Field evaluation}

The 12 common bean lines were assessed using 22 S. sclerotiorum isolates with one isolate per experiment in completely randomized blocks with 3 replications. Plots consisted of $1-\mathrm{m}$ rows (spacing of $0.5 \mathrm{~m}$ ), with 15 plants per plot. The 10 most vigorous plants in the plot were inoculated by the straw test method (Petzoldt and Dickson, 1996; Terán and Singh, 2009). The experiments were performed across 3 assessment periods in the 2011 dry crop season (April 18-25), the 2011 winter crop season (September 10-17), and the 2012 dry crop season (April 8-15). In the 2011 dry crop season, 10 S. sclerotiorum isolates were used, and 2 of the isolates were chosen for use in the other crop seasons for determination of the effect of the crop season-by-isolate interaction. The second assessment was performed in the 2011 winter crop season using 9 S. sclerotiorum isolates, 2 of them were the same as those used in the first crop season. Seven S. sclerotiorum isolates were used in the third assessment, in the 2012 dry crop season, with 5 different isolates and 2 that were the same as those used in the first and second assessments. Inoculations were performed during the fourth week after sowing. Eight days after the inoculations, assessments were conducted according to a diagrammatic scale from 1 to 9 (Terán et al., 2006), where 1 = plants without symptoms and $9=$ plant death.

The environmental conditions for the 3 assessment periods were as follows: 1) the average temperature varied from $21.0^{\circ}$ to $23.0^{\circ} \mathrm{C}$, humidity ranged from 65.0 to $70.0 \%$, and there was no precipitation; 2) the average temperature varied from $17.2^{\circ}$ to $23.9^{\circ} \mathrm{C}$, humidity ranged from 42.0 to $71.0 \%$, and there was no precipitation; and 3) the average temperature varied from $20.3^{\circ}$ to $26.1^{\circ} \mathrm{C}$, humidity ranged from 57.5 to $91.0 \%$, and there was an average of $6.9 \mathrm{~mm}$ of rainfall per day. During the first and second assessment periods, the experiments were sprinkle-irrigated twice each with $20 \mathrm{~mm}$ of water.

\section{Greenhouse evaluation}

The 12 common bean lines were assessed with regard to their reactions to white mold using the straw test inoculation method (Petzoldt and Dickson, 1996; Terán and Singh, 2009) 3 weeks after sowing for a comparative analysis of the results obtained in a field setting. Isolate 12 , the most aggressive in the field evaluations, and isolate 8 , common to the 3 crop seasons in the field, were used. Each isolate was used in an experiment in a completely randomized block design with 3 replications. Each plot consisted of 4 plants sown in a 4-L plastic pot containing sand and a substrate, for a total of 12 plants from each line. The greenhouse was kept at $25^{\circ} \mathrm{C}$ with $85 \%$ moisture and irrigation. The lines were assessed 8 days after inoculation according to a diagrammatic scale from 1 to 9 (Terán et al., 2006) where 1 = plants without symptoms and $9=$ plant death. The Pearson correlation coefficient was estimated between the mean values of the lines inoculated with the 2 isolates in the greenhouse and field trials. 


\section{Data analysis}

Based on the mean scores of the plots obtained through evaluation of resistance of the common bean lines to white mold, individual ANOVA was performed for each isolate for all the crop seasons. A pooled analysis involving all the experiments according to the following model was also conducted:

$$
Y_{i j k z}=m+b_{j(k z)}+t_{i}+l_{k}+s_{z}+t l_{i k}+t s_{i z}+s l_{z k}+t s l_{i z k}+\bar{e}_{i j k z}
$$

where: $Y_{i j k}=$ observation in regard to line $i$, in block $j$, in crop season $k ; m=$ overall mean; $b_{j(k z)}=$ random effect of block $j$, within isolate $k$, within crop season $z ; s_{z}=$ fixed effect of crop season $z$, with $(z=1,2$, and 3$) ; t_{i}=$ fixed effect of line $i$, with $(i=1,2,3 \ldots 12) ; l_{k}=$ fixed effect of isolate $k$, with $(k=1,2,3 \ldots 22) ; t l_{i k}=$ fixed effect of the interaction of line $i$ and isolate $k ; t s_{i z}$ $=$ fixed effect of the interaction of line $i$ and crop season $z ; s l_{z k}=$ fixed effect of the interaction of crop season $z$ and isolate $k$; $t s l_{i z k}=$ fixed effect of the interaction of line $i$, crop season $z$, and isolate $k$; and $\overline{\mathrm{e}}_{i j k z}=$ random effect of experimental error. The Pearson correlation coefficient was also estimated. Analyses were performed with the assistance of the SAS ${ }^{\circledR}$ software (SAS Institute, 2000).

Diallel analysis was performed according to the methodology proposed by Melo and Santos (1999) via the following model:

$$
Y_{i j}=\mu+r_{i}+\underset{j}{a}+s_{i j}+e_{i j}
$$

where $Y_{i j}=$ severity of the disease exhibited by line $i$ when inoculated with isolate $j$; $\mu=$ overall mean; $r_{i}=$ fixed effect of horizontal resistance of line $i$; $a_{j}=$ fixed effect of the aggressiveness of isolate $j ; s_{i j}=$ fixed effect of vertical resistance of line $i$ inoculated with isolate $j$; and $e_{i j}=$ experimental error associated with observation $Y_{i j}$, with the assistance of the $\mathrm{SAS}^{\circledR}$ software (SAS Institute, 2000). A GGE biplot analysis was also performed through use of the GGE Biplot software (Yan and Kang, 2002) for the purpose of estimating the genetic resistance of the lines, the genetic effect of aggressiveness of the isolates, and the isolate-by-line interaction component. This procedure uses principal component analysis and may complement diallel analysis.

\section{RESULTS}

\section{Individual and pooled ANOVA}

In the field evaluations, the coefficient of variation $(\mathrm{CV} \%)$ for individual ANOVA ranged from 8.13 to $18.78 \%$ for isolate 6 in the 2012 dry crop season and isolate 3 in the 2011 dry crop season, respectively (Table 2). The CV\% was $<14 \%$ in 16 of the 22 experiments (isolates). Since $\mathrm{CV} \%$ is highly affected by the mean value, selective accuracy $\left(\hat{\mathrm{r}}_{\hat{\mathrm{gg}}}\right)$ was estimated; the calculations indicated that there was excellent precision in these 16 experiments, with $\hat{\mathrm{r}}_{\hat{\mathrm{g} g}}>80 \%$ (Resende, 2007). The $\hat{\mathrm{r}}_{\hat{\mathrm{g} g}}$ estimates in most of the experiments were high, with the exception of isolate 8, which exhibited low accuracy of 35.04 and $39.96 \%$ in the 2011 winter crop and 2012 dry crop seasons, respectively. It is noteworthy that all the experiments were performed contiguously in each crop season and were subjected to the same experimental procedures. Therefore, the results of those experiments that presented a greater $\mathrm{CV}$ or lower 
accuracy were primarily influenced by the less aggressive isolates that were less efficient in inducing a differential reaction in the lines, thus generating a low overall mean value.

Table 2. Estimates from individual ANOVA of the reaction of common bean lines to each isolate of Sclerotinia sclerotiorum, including mean reaction (MR), coefficient of variation (CV, \%), selective accuracy $\left(\mathrm{r}_{\mathrm{g} \hat{\mathrm{g}}}, \%\right)$, mean square of lines (MS), probability of the F test for the MS (P), and season of the experiments. Lavras, MG, Brazil, 2012.

\begin{tabular}{|c|c|c|c|c|c|c|}
\hline Isolate & MR & CV (\%) & $\mathrm{r}_{\mathrm{g} \hat{\mathrm{g}}}(\%)$ & MS & $P$ & Season \\
\hline 1 & 3.92 & 12.33 & 91.79 & 1.48 & 0.0001 & 1 \\
\hline 2 & 4.76 & 15.01 & 84.42 & 1.77 & 0.0062 & 1 \\
\hline 3 & 3.43 & 18.78 & 71.73 & 0.85 & 0.0808 & 1 \\
\hline 4 & 4.03 & 18.71 & 80.67 & 1.62 & 0.0171 & 1 \\
\hline 5 & 4.60 & 16.22 & 69.51 & 1.07 & 0.0931 & 1 \\
\hline 6 & 4.63 & 13.90 & 88.85 & 1.96 & 0.0009 & 1 \\
\hline 7 & 4.41 & 9.97 & 93.74 & 1.59 & 0.0000 & 1 \\
\hline 8 & 4.43 & 16.07 & 81.51 & 1.18 & 0.0163 & 1 \\
\hline 9 & 4.27 & 14.07 & 78.26 & 0.93 & 0.0280 & 1 \\
\hline 10 & 4.53 & 18.22 & 42.47 & 0.83 & 0.3348 & 1 \\
\hline 11 & 5.19 & 12.96 & 90.07 & 2.39 & 0.0005 & 2 \\
\hline 12 & 6.39 & 9.23 & 83.81 & 1.17 & 0.0082 & 2 \\
\hline 13 & 5.42 & 13.15 & 80.02 & 1.41 & 0.0198 & 2 \\
\hline 6 & 4.60 & 15.25 & 86.20 & 1.49 & 0.0036 & 2 \\
\hline 14 & 5.05 & 9.30 & 83.37 & 0.73 & 0.0092 & 2 \\
\hline 15 & 4.53 & 12.10 & 79.35 & 0.81 & 0.0227 & 2 \\
\hline 16 & 2.93 & 13.28 & 79.09 & 0.41 & 0.0334 & 2 \\
\hline 17 & 4.34 & 12.14 & 88.28 & 1.26 & 0.0016 & 2 \\
\hline 8 & 3.38 & 18.00 & 35.04 & 0.43 & 0.3963 & 2 \\
\hline 18 & 3.24 & 10.80 & 82.68 & 0.39 & 0.0103 & 3 \\
\hline 8 & 3.79 & 10.94 & 39.96 & 0.21 & 0.3470 & 3 \\
\hline 19 & 4.02 & 11.74 & 88.70 & 1.05 & 0.0011 & 3 \\
\hline 20 & 3.74 & 10.50 & 75.05 & 0.35 & 0.0470 & 3 \\
\hline 6 & 4.96 & 8.13 & 91.47 & 1.02 & 0.0001 & 3 \\
\hline 21 & 4.85 & 9.15 & 89.51 & 0.99 & 0.0006 & 3 \\
\hline 22 & 4.04 & 15.56 & 63.34 & 0.66 & 0.1472 & 3 \\
\hline
\end{tabular}

In the pooled ANOVA that included all of the isolates, wide genetic variation was observed among the levels of resistance of the lines and the levels of aggressiveness of the isolates $(\mathrm{P}<0.001)$. The lack of significance of the isolate-by-line interaction is especially noteworthy, indicating a uniform response of the lines to the different isolates $(\mathrm{P}=0.30)$. Once more, there was high selective accuracy (98.76\%), confirming high experimental precision. The genetic diversity of the reaction of the lines and of the aggressiveness of the isolates is shown in Table 3.

Table 3. Mean reaction values of the lines to the different isolates and mean aggressiveness values of the isolates inoculated into the different lines in the field. Lavras, MG, Brazil, 2012.

\begin{tabular}{|c|c|c|c|c|c|}
\hline Line (P) & Mean value ${ }^{1}$ & Isolate (I) & Mean value $^{1}$ & Isolate (I) & Mean value $^{1}$ \\
\hline P1 (L28) & $4.46^{\mathrm{a}}$ & I1-(Ijaci 05) & $3.97^{\mathrm{c}}$ & I12-(UFLA27) & $6.38^{\mathrm{a}}$ \\
\hline P2 (L10) & $4.78^{a}$ & I2-(UFLA29) & $4.68^{b}$ & I13-(UFLA28) & $5.42^{\mathrm{a}}$ \\
\hline P3 (L19) & $4.08^{b}$ & I3-(UFLA37) & $3.40^{\mathrm{c}}$ & I14-(UFLA49) & $5.02^{\mathrm{b}}$ \\
\hline P4 (L14) & $4.58^{\mathrm{a}}$ & I4-(UFLA38) & $4.03^{c}$ & I15-(UFLA48) & $4.54^{\mathrm{b}}$ \\
\hline P5 (L92) & $4.00^{\mathrm{b}}$ & I5-(UFLA39) & $4.55^{\mathrm{b}}$ & I16-(UFLA66) & $2.91^{\mathrm{c}}$ \\
\hline P6 (L89) & $3.74^{\mathrm{b}}$ & I6-(UFLA44) & $4.72^{\mathrm{b}}$ & I17-(UFLA91) & $4.40^{\mathrm{b}}$ \\
\hline P7 (L88) & $3.92^{\mathrm{b}}$ & I7-(UFLA47) & $4.39^{\mathrm{b}}$ & I18-(UFLA10) & $3.25^{\mathrm{c}}$ \\
\hline P8 (L112) & $4.21^{\mathrm{b}}$ & I8-(Goiânia4) & $3.84^{\mathrm{c}}$ & I19-(UFLA22) & $4.02^{\mathrm{c}}$ \\
\hline P9 (L125) & $4.47^{\mathrm{a}}$ & I9-(UFLA36) & $4.27^{\mathrm{c}}$ & I20-(UFLA34) & $3.74^{\mathrm{c}}$ \\
\hline P10 (L138) & $4.73^{\mathrm{a}}$ & I10-(UFLA30) & $4.53^{\mathrm{b}}$ & I21-(UFLA46) & $4.86^{\mathrm{b}}$ \\
\hline P11 (L667) & $3.93^{\mathrm{b}}$ & I11-(UFLA03) & $5.15^{\mathrm{b}}$ & I22-(UFLA51) & $4.04^{\mathrm{c}}$ \\
\hline P12 (Cor.) & $5.38^{\mathrm{a}}$ & & & & \\
\hline
\end{tabular}

${ }^{1}$ Mean values followed by different letters are genetically heterogeneous according to the Scott-Knott test (1974) at $5.09 \%$ probability. 
The mean reaction of each line represents its mean effect when inoculated with various isolates. Thus, the lines that presented greater levels of resistance were P6 (3.74), P7 (3.92), and P11 (3.93) (Table 3). The lines that presented the greatest mean reaction values were P12 (5.38; the susceptible Corujinha control), P10 (4.73), and P4 (4.58), thus, presenting lower levels of resistance. In relation to the isolates, the broad genetic differences among the mean aggressiveness values are also noteworthy (Table 3). Isolates I12 (6.38) and I13 (5.42) were the most aggressive, while 10 isolates expressed intermediate aggressiveness, and the remaining 10 were among the least aggressive.

There was a significant difference in the crop season-by-isolate interaction $(\mathrm{P}<0.01)$, which allows inferences to be made regarding the effect of the environment on the aggressiveness of the isolates, although only 2 isolates (I6 and I8) were used for estimating the source of variation. The different origins of the isolates, especially with regard to the temperature differences of those locations, explain the differential aggressiveness values across the various crop seasons. This interaction also explains the small line-by-crop season interaction $(\mathrm{P}=0.04)$, indicating that they slightly varied their reactions in the face of the mean aggressiveness value of the isolates by crop season.

When the reaction of the lines to 2 isolates in a greenhouse was assessed, there was a genetic difference $(\mathrm{P}<0.01)$ for both isolates. The correlation $(r=0.79 * *)$ among the reactions in the field and greenhouse observed for isolate 12, the most aggressive, showed that the evaluations in the 2 environments generated similar results and indicates that the straw test may also be used in the field. The lack of correlation $(r=0.53)$ of the reactions of the lines in the 2 environments for isolate 8 was caused by the fact that this isolate was not very aggressive in the field and the lines were not differentiated with regard to resistance. The low magnitude CVs (\%) were also similar to the lowest values seen in the field evaluations. Nevertheless, it was observed that the mean reactions of the evaluations in the greenhouse were greater (5.79 and 7.08 for isolates 8 and 12, respectively) than those in the field (3.84 and 6.38 for isolates 8 and 12, respectively). In the greenhouse, the temperature and moisture conditions were more uniform and certainly more favorable for development of the disease. However, for evaluation under the pot condition in the greenhouse, the escape mechanisms, such as bushy growth habit, differed from those under the crop conditions, which may affect estimates of the level of resistance of the common bean lines and the levels of aggressiveness of the isolates.

\section{Partial diallel analysis}

The highly significant $(\mathrm{P}<0.001)$ general reaction capacity $(\mathrm{GRC})$ and the general aggressiveness capacity confirmed that these sources of variation were predominant. Nevertheless, the significant $(\mathrm{P}=0.006)$ specific reaction capacity $(\mathrm{SRC})$ is, initially, an indication of vertical resistance. However, its low magnitude, approximately 30 times less than that of the GRC, may also represent differences in variability of the reactions of the lines to the isolates, as well as the difference in variability of the aggressiveness values of the isolates to the lines. These differences in variability arise from the fact that the evaluations were conducted across 3 different crop seasons and using isolates originating from locations with varying environmental conditions, especially with regard to temperature. 
In the face of the significant variability of reactions of the lines, the genetic effect of resistance of each line $\left(r_{i}\right)$ was estimated (GRC), and the lowest estimates were observed for lines 89 (P6), 88 (P7), 667 (P11), and 92 (P5) (Figure 1a). In this case, the lower the value of $r_{i}$, the greater the level of horizontal resistance of the line because, based on the diagrammatic scale, a lower score indicates greater resistance.

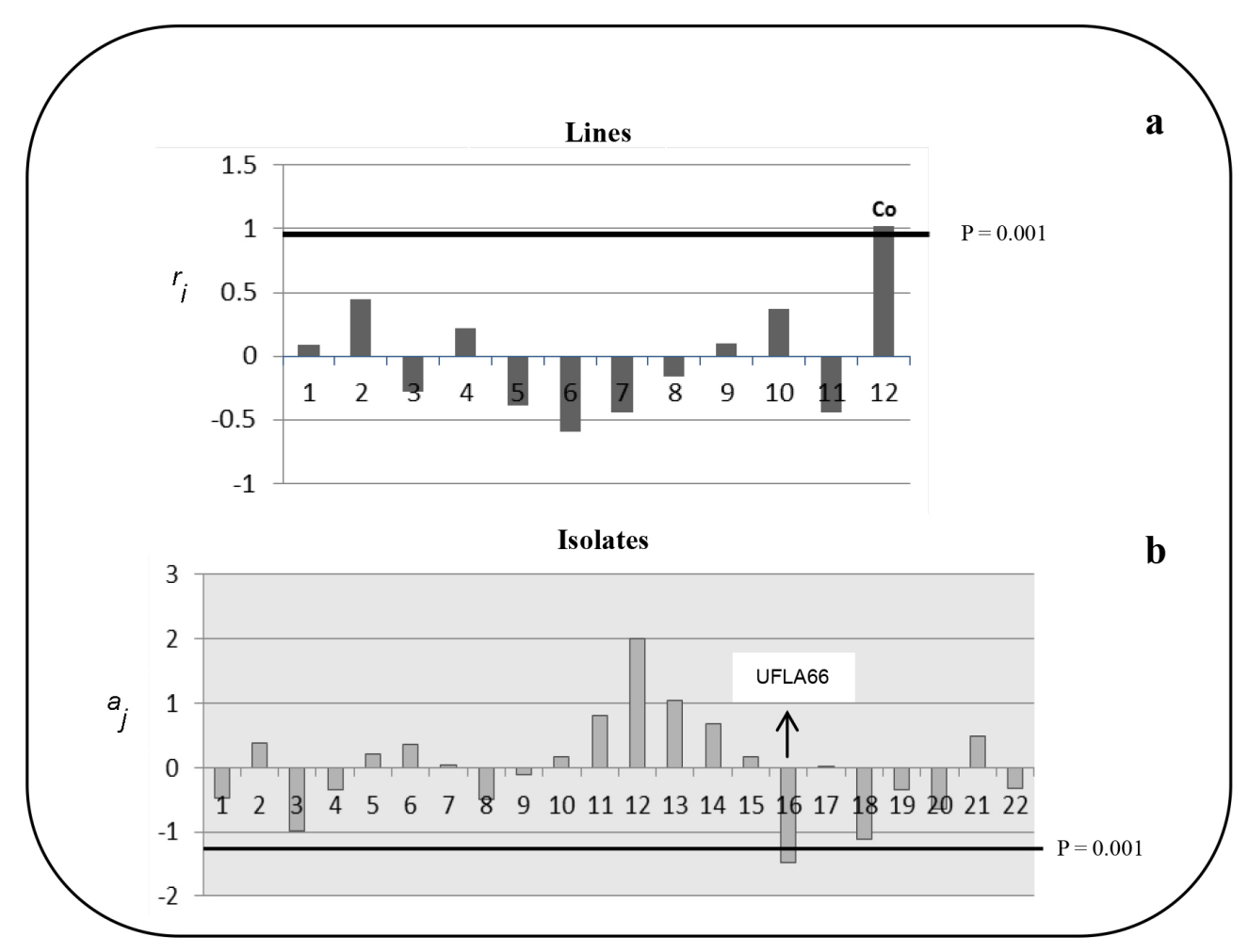

Figure 1. a. Magnitudes of the genetic effects $\left(r_{i}\right)$ of the reaction of common bean lines (P1-P12) to Sclerotinia sclerotiorum isolates and their differences from the susceptible control Corujinha $(12=\mathrm{P} 12=\mathrm{Co})$ by the $t$-test. $\mathbf{b}$. Magnitudes of the genetic effects of the aggressiveness values $\left(a_{j}\right)$ of the S. sclerotiorum isolates (I1-I22) inoculated in the common bean lines and their differences in relation to the least aggressive isolate by the $t$-test $(16=\mathrm{I} 16=\mathrm{UFLA66})$.

Likewise, in relation to the broad variation in aggressiveness of the isolates, the genetic effect related to the level of aggressiveness of each isolate $\left(a_{j}\right)$ was estimated (the general aggressiveness capacity [GAC]), and isolates I12, I13, and I11 were the most aggressive (Figure 1b). This implies that they should be preferred for evaluation of the level of resistance of common bean genotypes. In this case, the greater the value of $a_{i}$, the greater the aggressiveness of the isolate. The least aggressive isolates were I16, I18, and I3.

In relation to the specific reaction capacity (SRC), which was significant, there is the possibility of estimating the specific effects for each line-by-isolate combination $\left(s_{i j}\right)$, albeit at a lower magnitude than that of the line and isolate effects (Cruz et al., 2004). The significant 
effects provide information on the lines and isolates that contributed the most to the interaction (Table 4). I4 and I11 were the isolates that most contributed to the SRC; and I6, I8, I10, I15, I16, I17, I19, I20, and I22 were the most stable. Lines P2, P6, P8, P9, and P10 most contributed to the SRC; and P1, P3, P4, and P7 were the most stable.

\begin{tabular}{|c|c|c|c|c|c|}
\hline Isolate & $\operatorname{SSRC}\left(s_{i j}\right)$ & Isolate & $\operatorname{SSRC}\left(s_{i j}\right)$ & Line & $\operatorname{SSRC}\left(s_{i j}\right)$ \\
\hline I1 & 1 & I13 & 1 & P1 & 0 \\
\hline I2 & 2 & I14 & 1 & P2 & 5 \\
\hline I3 & 1 & I15 & 0 & P3 & 0 \\
\hline I4 & 5 & I16 & 0 & P4 & 0 \\
\hline I5 & 2 & I17 & 0 & P5 & 1 \\
\hline I6 & 0 & I18 & 1 & P6 & 4 \\
\hline I7 & 2 & I19 & 0 & P7 & 0 \\
\hline I8 & 0 & $\mathrm{I} 20$ & 0 & P8 & 4 \\
\hline I9 & 1 & I21 & 1 & P9 & 4 \\
\hline I10 & 0 & I22 & 0 & P10 & 3 \\
\hline I11 & 5 & & & P11 & 1 \\
\hline I12 & 1 & & & P12 (Corujinha) & 2 \\
\hline
\end{tabular}

\section{Analysis through the GGE biplot}

According to the principal component analysis of the line reactions, P6, P7, P11, P5, $\mathrm{P} 3$, and $\mathrm{P} 8$ were the most resistant to the 22 S. sclerotiorum isolates; line P12 was the most susceptible (Corujinha control); and lines P4, P1, P10, and P2 presented some level of resistance (Figure 2a). The lines located near each other in the graph, such as the clusters of lines P5, P11, and P3; lines P6 and P7; lines P8 and P9; and lines P4, P1, P10, and P2 show particular standards of resistance in reaction to the isolates and probably contain particular groups of resistance alleles. Graph analysis also allows inferences to be made regarding the contribution of each line to the isolate-by-line interaction (i.e., regarding the stability of the reaction of each line when inoculated with different isolates). It may thus be seen that the lines that most contributed to the interaction were P5, P8, and P9 (Figure 2b). Nevertheless, lines P5 and P8 had significant levels of resistance, yet they are very unstable when inoculated with different S. sclerotiorum isolates. Lines P2, P3, P6, and P7 were the most stable, and the last 3 were among the most resistant (Figure 2b).

I12 and I13, located near each other, were the most aggressive in a similar analysis of isolate aggressiveness and as such, they belong to the same group and may be characterized as having the same standard of aggressiveness. Isolate I16 was the least aggressive (Figure 3a). The formation of 2 more groups of less aggressive isolates was also observed; one group was comprised of isolates I18, I20, I19, and I22, and another group was composed of the isolates I1, I9, I7, I2, and I4. The isolates belonging to the same group may exhibit the same standard of aggressiveness (Figure 3a).

With regard to the isolates, those that most contributed to the interaction were I13, I11, I2, I4, and I8 in the 2011 winter crop and 2011 dry crop seasons (Figure 3b). Some of the most aggressive isolates were among the most unstable isolates, including I13 and I11. 

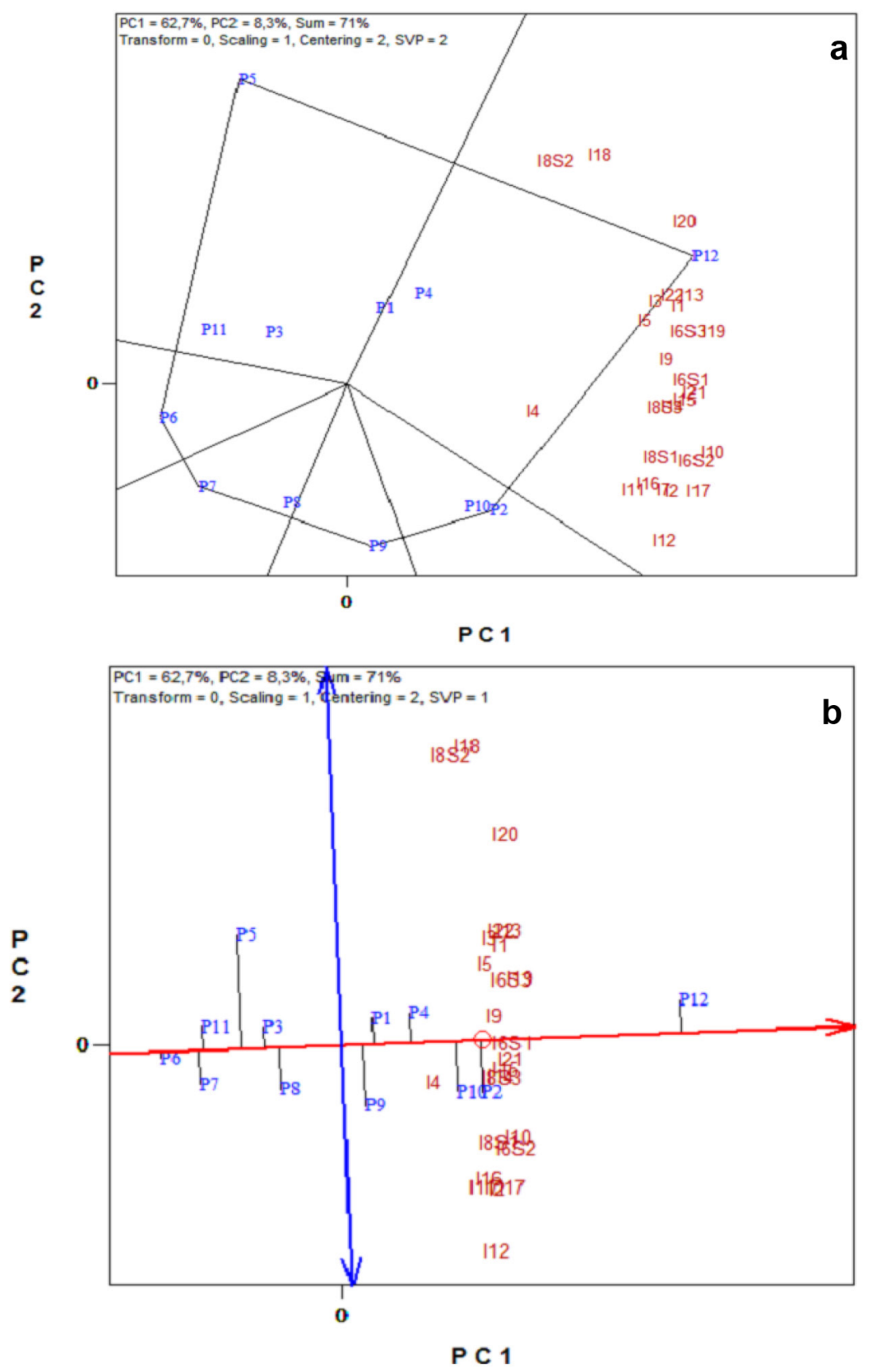

Figure 2. a. GGE biplot based on reaction of the 12 common bean lines to the 22 Sclerotinia sclerotiorum isolates. Isolates 6 and 8 are accompanied by S1, S2 or S3 because they were used in the three crop seasons (S). b. Stability of the 12 common bean lines. Principal component $1(\mathrm{PC} 1)=62.7 \%$ and $\mathrm{PC} 2=8.3 \%$, corresponding to $71 \%$ of total variation. 

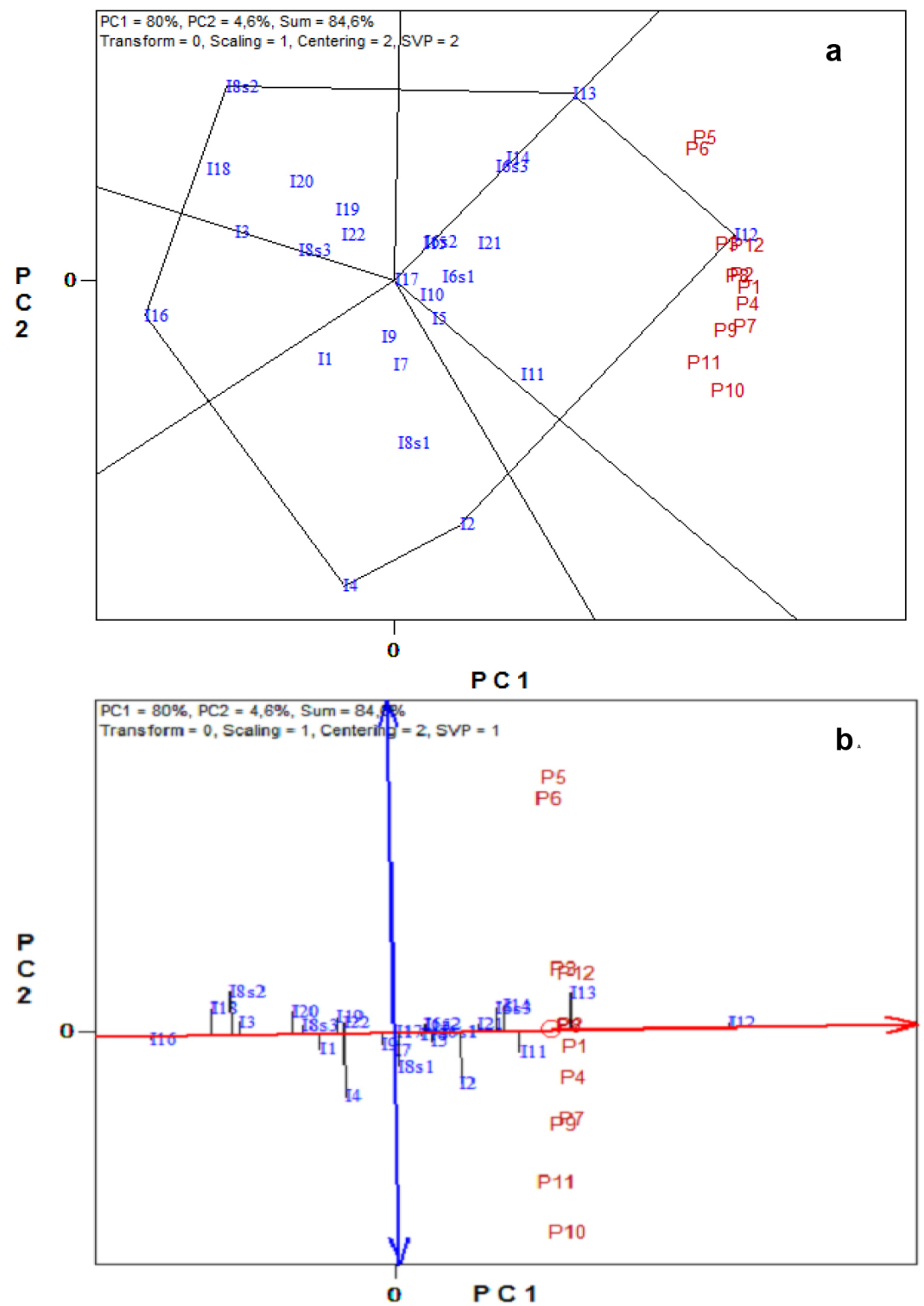

Figure 3. a. GGE biplot based on the aggressiveness of the 22 Sclerotinia sclerotiorum isolates to the 12 common bean lines. Isolates 6 and 8 are accompanied by S1, S2 or S3 because they were used in the three crop seasons (S). b. Stability of the 22 S. sclerotiorum isolates. $\mathrm{PC} 1=80.0 \%$ and $\mathrm{PC} 2=4.6 \%$, corresponding to $84.6 \%$ of total variation.

\section{DISCUSSION}

Various studies of white mold in the common bean have used the straw test method, and inoculations are normally performed in a greenhouse (Miklas et al., 1998, 1999; Hall and Phillips, 1997, 1998; Miklas, 2001; Steadman et al., 2001, 2003; Miklas and Delorme, 2003; Ender 
and Kelly, 2005; Mkwaila et al., 2011; Soule et al., 2011). However, space limitations in a greenhouse make evaluations of a large number of genotypes impractical. Another limitation is that escape mechanisms are not considered, which may underestimate white mold resistance for crop conditions. The experimental precision in the 2 environments is similar (Terán and Singh, 2010) and, therefore, field results are equally reliable. As such, when many plants have to be evaluated, preference should be given to field experiments, thus allowing for more reliable results.

This study detected wide variability among the isolates, lines, and a strong isolate-byenvironment interaction, which may explain the great variation in aggressiveness. It was not possible to assess all of the isolates across all of the crop seasons. Perhaps for that reason, the magnitude of this interaction was $25-30 \%$ of the isolate and line effects. Even so, it may be inferred that the aggressiveness of the isolate may vary depending on the crop season evaluated, being slightly greater when evaluated in the winter because the winter season has milder temperatures that are more favorable for the pathogen. In addition, the aggressiveness of each isolate may also be related to its origin. Those from hotter locations are generally less aggressive because the experiments were conducted at an altitude of $915 \mathrm{~m}$, which is considered to be a higher altitude tropical climate with milder temperatures, especially in the fall and winter. Wide variability in the aggressiveness of different isolates related to different reproductive compatibilities and the origin of each one has been verified (Otto-Hanson et al., 2011; Lehner et al., 2013). It is important to highlight that the most highly aggressive isolate allows maximum discrimination of hosts with regard to the level of resistance, as was observed for isolate I13 and, primarily, I12, which was the most stable (Yan and Falk, 2002).

In a diallel analysis for studying the pathogen-by-host interaction, there was a high correlation between the GRC and the horizontal resistance of the hosts, as well as the GAC of the pathogens and their genetic effects of aggressiveness (Melo and Santos, 1999). A great deal of the variation in the line reactions was explained by the genetic variation among them (i.e., by the GRC and variation in the aggressiveness of the isolates, or GAC). Therefore, the estimated genetic effect in relation to the level of line resistance reflects the proportion of horizontal resistance alleles present. In a survey of the literature, at least 21 genomic regions (quantitative trait loci) of the common bean are involved in resistance to white mold, confirming the quantitative nature of this resistance (Soule et al., 2011). Likewise, the estimate of the genetic effect of aggressiveness also reflects the proportion of aggressiveness alleles of each isolate and, possibly, a genetic control equivalent to that of horizontal resistance.

Among the lines with a greater level of resistance, P11 was derived from backcrossing, in which the resistance donor parent was the Ex Rico 23 line of Central American origin. Lines P5, P6, and P7 were also derived from backcrosses, but the resistance donor parent was the G122 line of Andean origin. Therefore, there is the possibility that their resistance alleles are different and, consequently, the lines selected originating from different sources of resistance may be crossed to generate recombinant progenies with higher levels of resistance (Cruz et al., 2004).

Significant specific reaction capacity (SRC) may indicate the presence of vertical resistance of the host and of specific virulence in the pathogen. Nevertheless, the magnitude of the interaction is approximately 34 times less than the effect of the lines (GRC) and 45 times less than the effect of the isolates (GAC), thus characterizing only horizontal resistance, and the occurrence of this small interaction is entirely possible (Parlevliet, 1981; Nicks et al., 2011). In addition, the isolate-by-crop season interaction, mainly arising from the different origins of the isolates, allows inferences to be made regarding their different aggressiveness values and their contribution to the isolate-by-line interaction. 
The results of the GGE biplot analysis were similar to those of the diallel analysis, especially for characterizing the lines with regard to the level of resistance and the isolates with regard to the level of aggressiveness (Yan and Falk, 2002). The advantage of this analysis is pooling genetically similar genotypes according to origin from the lines based on the 2 sources of resistance. Therefore, it may also be deduced that the isolates belonging to different groups certainly carry different aggressiveness alleles.

The GGE biplot and diallel methods could be used to make inferences regarding the stability of the lines and the isolates. In the case of the diallel method, the genetic effect, which is due only to the effect of the interaction of each line-by-isolate combination, may be estimated (Cruz et al., 2004). Considering only the significant estimates of these effects (Table 4) and comparing them to the stabilities of the lines (Figure 2b) and isolates (Figure 3b), some of the results were in disagreement. With regard to the lines, P6 was considered the most stable by the GGE biplot method but was unstable by the diallel method; P5 was the least stable by the GGE biplot method but its contribution to the interaction according to the diallel method was almost nonexistent. In relation to the isolates, the instability of I4 was foreseen by the 2 methods, although there were discrepancies with regard to isolates I8, I11, and I13. It is important to emphasize that only the first 2 principal components, which explained 71 and $84.6 \%$ of the total variation of the genetic effects and line-by-isolate interaction, respectively, are considered in the GGE procedure. In addition, the GGE biplot does not include a statistical test of the estimates of the genetic effects or the line-by-isolate interaction. However, in the diallel analysis, the estimates of the genetic effects of resistance $\left(r_{i}\right)$ and aggressiveness $\left(a_{j}\right)$, as well as the effect of the interaction $\left(s_{i j}\right)$, were all tested by the $t$-test. Moreover, these estimates were obtained from the total variation of the genotypes and the line-by-isolate interaction. Therefore, both procedures are useful but the diallel method is more reliable, especially when studying the line-by-isolate interaction, which, in this case, represented a lower proportion of the phenotypic variation.

\section{ACKNOWLEDGMENTS}

The authors would like to acknowledge the FAPEMIG for granting a scholarship, the Graduate Studies Program in Plant Genetics and Breeding of Universidade Federal de Lavras and resources for the project.

\section{REFERENCES}

Boland GJ and Hall R (1994). Index of plant hosts of Sclerotinia sclerotiorum. Can. J. Plant Pathol. 16: 93-108.

Buiate EAS, Souza EA de, Vaillancourt L and Resende I (2010). Evaluation of resistance in sorghum genotypes to the causal agent of anthracnose. Crop Breed. Appl. Biotechnol. 10: 166-172.

Carneiro FF, Zeviani WM, Bosco JB and Carvalho RSB (2011). Minimum number of common bean plants per plot to assess field resistance to white mold. Crop Breed. Appl. Biotechnol. 11: 358-364.

Cruz CD, Regazzi AJ and Carneiro PCS (2004). Modelos Biométricos Aplicados ao Melhoramento Genético. Vol. 1. 3rd edn. UFV Press, Viçosa.

Ender M and Kelly JD (2005). Identification of QTL associated with white mold resistance in common bean. Crop Sci. 45: 2482-2490.

Hall R and Phillips LG (1997). Resistance of white bean to white mold: field evaluation of straw test. Annu. Rep. Bean Improv. Coop. 40: 138-139.

Hall R and Phillips LG (1998). Field evaluation of the straw test for assessing resistance of dry bean to white mold. Annu. Rep. Bean Improv. Coop. 41: 171-172.

Huang HC, Mundel HH and Erickson RS (2003). Effect of physiological resistance and plant architecture on yield of dry bean under disease pressure of white mold (Sclerotinia sclerotiorum). Plant Prot. Bull. Taiwan 45: 169-176. 
Kim HS, Sneller CH and Diers BW (2000). Inheritance of partial resistance to Sclerotinia stem rot in soybean. Crop Sci. 40: 55-61.

Kimati H, Amorin L, Rezende JAM and Bergamin Filho A (2005). Manual de Fitopatologia: Doenças das Plantas Cultivadas. 4th edn. Agronômica Ceres, São Paulo.

Kolkman JM and Kelly JD (2002). Agronomic traits affecting resistance to white mold in common bean. Crop Sci. 42: 693-699.

Kolkman JM and Kelly JD (2003). QTL conferring resistance and avoidance to white mold in common bean. Crop Sci. 43: 539-548.

Lehner MS, Paula Júnior TJ, Lima RC and Vieira RF (2013). Mycelial compatibility grouping and aggressiveness of Sclerotinia sclerotiorum isolates from four states of Brazil. Annu. Rep. Bean Improv. Coop. 56: 53-54.

Lima IA, Couto KR, Leite ME and Santos JB (2009). Seleção de Progênies de Feijoeiro Tipo Carioca de Populações de Retrocruzamento para Resistência ao Mofo Branco. Anais do 50 Congresso Brasileiro de Melhoramento de Plantas, Guarapari.

Lobo M Jr and Nasser LCB (2007). Mofo branco pode limitar o agronegócio da soja, feijão e girassol em áreas infestadas. Inf. Agromen 4: 6-8.

Maxwell JJ, Brick MA, Byrne PF and Schwartz HF (2007). Quantitative trait loci linked to white mold resistance in common bean. Crop Sci. 47: 2285-2294.

Melo LC and Santos JB (1999). Identification of resistant genotypes considering polygenic systems in host-pathogen interaction. Genet. Mol. Biol. 22: 601-608.

Miklas PN and Delorme R (2003). Identification of QTL conditioning resistance to white mold in snap bean. J. Am. Soc. Hort. Sci. 128: 564-570.

Miklas PN, Grafton NF, Kelly JD and Schwartz HF (1998). Registration of four white mold resistant dry bean germplasm lines: 19365-3, I9365-5, I9365-31, and 92BG7. Crop Sci. 38: 1728.

Miklas PN, Delorme R, Hannan R and Dickson MH (1999). Using a subsample of the core collection to identify new sources of resistance to white mold in common bean. Crop Sci. 39: 569-563.

Miklas PN, Johnson WC, Delorme R and Gepts P (2001). QTL conditioning physiological resistance and avoidance to white mold in dry bean. Crop Sci. 41:309-315.

Mkwaila W, Terpstra KA, Ender M and Kelly JD (2011). Identification of QTL for agronomic traits and resistance to white mold in wild and landrace germplasm of common bean. Plant Breed. 130: 665-672.

Otto-Hanson L, Steadman JR, Higgins R and Eskridge KM (2011). Variation in Sclerotinia sclerotiorum bean isolates from multisite resistance screening locations. Plant Dis. 95: 1370-1377.

Parlevliet JE (1981). Disease Resistance in Plants and its Consequences for Plant Breeding. In: Plant Breeding II (Frey KJ, ed.). The Iowa State University, Ames.

Pereira R (2013). Reação de Genótipos de Feijão e Virulência de Isolados do Agente Causal da Mancha Angular. Master's thesis, Universidade Federal de Lavras, Lavras.

Petzoldt R and Dickson MH (1996). Straw test for resistance to white mold in beans. Annu. Rep. Bean Improv. Coop. 39: $142-143$.

Resende MDV (2007). Matemática e Estatística na Análise de Experimentos de Campo. Embrapa, Curitiba.

SAS Institute (2000). SAS Language and Procedures: Usage. Version 8.1. Statistical Analysis System Institute, Cary.

Soule M, Porter L, Medina J and Santana JP (2011). Comparative QTL map for white mold resistance in common bean, and characterization of partial resistance in dry bean lines VA19 and 19365-31. Crop Sci. 51: 123-139.

Steadman J, Eskridge K, Costa J and Grafton K (2001). Evaluation of sources of resistance to Sclerotinia sclerotiorum in common bean with five test methods at multiple locations. Annu. Rep. Bean Improv. Coop. 44: 89-90.

Steadman JR, Eskridge KM, Powers K and Kurowski C (2003). Identification of partial resistance to Sclerotinia in field and greenhouse tests at multiple locations. Annu. Rep. Bean Improv. Coop. 46: 225-226.

Terán H and Singh SP (2008). Response of dry bean genotypes with different levels of resistance to Sclerotinia sclerotiorum to three inoculation methods. Annu. Rep. Bean Improv. Coop. 51: 218-219.

Terán H and Singh SP (2009). Efficacy of three greenhouse screening methods for the identification of physiological resistance to white mold in dry bean. Can. J. Plant Sci. 89: 755-762.

Terán H and Singh SP (2010). Gamete and recurrent selection for improving physiological resistance to white mold in common bean. Can. J. Plant Sci. 90: 153-162.

Terán H, Lema M, Schwartz HF and Duncan R (2006). Modified Petzoldt and Dickson scale for white mold rating of common bean. Annu. Rep. Bean Improv. Coop. 49: 115-116.

Voysest OV (2000). Mejoramiento Genetico Del Frijol (Phaseolus vulgaris) Legado de Variedades de América Latina (1930-1999). CIAT, Cali.

Yan W and Falk DE (2002). Biplot analysis of host-by-pathogen interaction. Plant Dis. 86: 1396-1401.

Yan W and Kang SM (2002). Biplot Analysis of Host Genotype-by-Pathogen Strain Interactions. In: GGE Biplot Analysis: A Graphical Tool for Breeders, Geneticists, and Agronomists. CRC Press, New York, 215-533. 